\title{
Internationalization of soil physics from an American perspective
}

\author{
M.B. Kirkham \\ Department of Agronomy, 2004 Throckmorton Plant Sciences Center, Kansas State University, Manhattan, KS 66506-5501, USA
}

Received March 11, 2012; accepted March 16, 2012

\begin{abstract}
A b s t r a c t. Upon the seventy-fifth anniversary of the Soil Science Society of America in 2011, a session was held at its annual meeting to document how the field has changed over the years. I was asked to give the long-term perspective for soil physics. I surveyed soil-physics research published by the society over the past six years (2005-2011) and compared it with a review done in 1961 upon the twenty-fifth anniversary of the society. Of the 299 papers in my survey, 186 came from outside the USA ( $62 \%$ of the total). Twenty-nine countries were represented with the People's Republic of China having the most papers (27 papers). In the 1961 review, only five countries outside the USA were cited. My survey showed that 48 papers $(16 \%)$ dealt with water, $35(12 \%)$ with mechanical properties, $19(6 \%)$ with aeration, $18(6 \%)$ with solute transport, $14(5 \%)$ with repellency, and $10(3 \%)$ with temperature. Of the non-USA papers in the survey, $27 \%$ gave no source of funding and the other $73 \%$ usually cited funding by the government of the corresponding author. Of the USA papers, $47 \%$ cited no source of funding. The results showed that soil-physics research has become heavily international.

$\mathrm{K}$ e y w o r d s: soil physics research, internationalization, funding of research
\end{abstract}

\section{INTRODUCTION}

Upon the seventy-fifth anniversary of the Soil Science Society of America in 2011, a special session was organized entitled, '75 Years of the SSSA While Looking Toward the Future'. Each participant in the session as asked to present a review of a particular aspect of soil science. I was asked to give the long-term perspective of soil physics. In 1961, Don Kirkham was asked to review soil physics upon the twentyfifth anniversary of the society (Kirkham, 1961). He covered research carried out between 1936, when the society was founded, and 1961. He reviewed work done in the states in the USA that had soil-physics programs, as well as five non-USA countries: The Netherlands, England, Australia, Belgium, and France.
The four factors that determine the physical and biophysical condition of the soil, as stated by Shaw (1952), are water, structure (mechanical properties), air, and temperature. In his review of the first 25 years of soil-physics research, Kirkham (1961) discussed research concerning water and structure. He mentioned no research related to soil aeration and temperature. He did document progress being made in physical measurements, noting that the famous, Nobel-Prize winning Dutch physicist, Heike Kamerlingh Onnes (1853-1926), said, 'Door Meten Tot Weten', which means 'By measurement comes knowledge'. Kirkham (1961) cited new methods to determine the water potential of the soil (tensiometers and pressure plates); an oxygen meter to measure soil aeration; new developments in wet sieving for soil structure measurements; and thermocouples to monitor soil temperature.

On the occasion of the fiftieth anniversary of the society, Cassel (1986) summarized soil-physics research published in the Soil Science Society of America Journal between 1961 and 1985. He divided the papers into five categories: water, air, heat, solids, and solute. The general topics of water and solute accounted for $75.9 \%$ of the soil-physics papers from 1961-1985. Cassel (1986) mentioned new methods being investigated, including neutron attenuation and gamma radiation attenuation. He did not cite country of origin of the papers.

In 2011, when I was asked to survey soil-physics research, it was too large to review since 1985 . So I limited my survey to the last six years (2005-2011). The purpose of this paper is to present the results of my review. 


\section{MATERIALS AND METHODS}

I surveyed the papers published in soil physics (called 'Division I') of the Soil Science Society of America Journal between the July-August, 2005, issue through the MayJune, 2011, issue. There were 36 issues in the survey, and 299 papers published in Division I in these six years. The survey included Soil Physics Notes. The number of papers per issue ranged from two (January-February 2006 issue) to fifteen (May-June 2007 issue and November-December 2010 issue). The number of papers per issue did not increase or decrease throughout the six years and averaged eight papers per issue. I divided the survey into the following seven topics:

- number of authors per paper,

- number of single- authored papers,

- women authors,

- countries from which papers came,

- states from which papers came,

- topics covered,

- and sources of funding for the research reported in the papers.

\section{RESULTS AND DISCUSSION}

There were 1035 authors for the 299 papers. Some of the authors were duplicates. That is, the same person wrote more than one paper. If one divides the number of authors by the number of papers (1035/299), one gets an average of 3.5 authors per paper.

Of the 299 papers, 18 were solely authored or $6 \%$ of the papers. Again, some of these authors were the same person. Some authors have published several, solely authored papers.

The low number of solely authored, soil-physics papers shows that most of the research has been done as a team.

It is difficult to identify women authors because of initials and unfamiliar names. However, to the best of my ability, I identified 42 papers out of the 299 that had women authors or $14 \%$ of the papers. Again, some were the same person. Kirkham (1961) cited no woman in his survey covering $1936-1961$. The value $14 \%$ is similar to the number of women that are now on boards. For example, in the most recent survey of women in the chemical industry, done each year by the American Chemical Society, 52 of the 399 directors at 42 leading U.S. chemical firms are women. That is an average of 1.2 female directors per company and 13\% of the total number of board positions (Tullo, 2011).

For the countries from which papers came, my survey was based upon the country of the corresponding author. Of the 299 papers, 186 came from outside the USA for $62 \%$ of the total. Twenty-nine countries were represented (Table 1). The results show that soil-physics research published in the USA is heavily international in contrast to 1961, when Kirkham (1961) cited work in only five non-USA countries.
T a b l e 1. Non-USA papers published in the Soil Physics Division of the Soil Science Society of America Journal between 2005 and 2011*

\begin{tabular}{lc}
\hline Country of origin & Number of papers \\
\hline P.R. China & 27 \\
Germany & 24 \\
Canada & 17 \\
France & 17 \\
Israel & 16 \\
Japan & 11 \\
Belgium & 10 \\
Australia & 8 \\
Spain & 7 \\
England & 6 \\
Italy & 6 \\
Taiwan & 6 \\
Denmark & 4 \\
New Zealand & 4 \\
Scotland & 3 \\
Switzerland & 3 \\
Hong Kong & 2 \\
India & 2 \\
South Korea & 2 \\
Sweden & 2 \\
\hline
\end{tabular}

*One paper from each of the following countries: Austria, Brazil, Czech Republic, Finland, Greece, Philippines, Poland, Slovak Republic, and Trinidad and Tobago.

The People's Republic of China had the most non-USA papers with 27 out of the 299 total in the survey (Table 1). This reflects the increased scientific output of this country. In 1996, the People's Republic of China and the USA published 25474 and 292513 scientific papers, respectively (Stengel, 2011). In 2008, these numbers were 184080 and 316317 , respectively (Stengel, 2011).

I also surveyed the states in the USA from which the papers came and based the survey on the state of the corresponding author. The domestic papers (113 papers or $38 \%$ of the 299 papers in the survey) came from federal and universities laboratories. Three federal laboratories (United States Department of Agriculture or USDA, Pacific Northwest, and Oak Ridge) published 39 papers (13\% of the papers in the survey) and universities published 74 papers $(25 \%)$ (Table 2). Thirty-five university laboratories were represented in the survey. In his survey, Kirkham (1961) mentioned six federal agencies in the USA [U.S. Geological Survey, Battelle Memorial Institute (now called Pacific Northwest), 
T a b l e 2. USA papers published in the Soil Physics Division of the Soil Science Society of America Journal between 2005 and 2011

\begin{tabular}{ll}
\hline Laboratory & Number of papers \\
\hline \multicolumn{1}{c}{ Federal laboratories } & \\
USDA* & 33 \\
Pacific Northwest & 4 \\
Oak Ridge & 2 \\
\hline & \\
Iowa State University & 7 \\
Utah State University & 5 \\
University California, Davis & 4 \\
University California, Riverside & 4 \\
Louisiana State University. & 4 \\
Desert Research Institute (Nevada) & 4 \\
University of Hawaii & 3 \\
North Carolina State University & 3 \\
North Dakota StateUniversity & 3 \\
Pennsylvania State University & 3 \\
University of Wisconsin & 3 \\
University of Wyoming & 3 \\
Auburn University & 2 \\
Kent State University & 2 \\
Oklahoma State University & 2 \\
Texas A and M University & 2 \\
Virginia Polytechnic and State University & \\
\hline & 2 \\
\hline
\end{tabular}

*USDA laboratories and number of papers from each: Beltsville, MD - 9; Ames, IA - 8; St. Paul, MN - 5; Fort Collins, CO - 3; Bushland, TX - 2; U.S. Salinity Lab., Riverside, CA - 2; Auburn, $\mathrm{AL}-1$; Watkinsville, GA-1; Oxford, MS - 1; Pendleton, OR - 1 .

**One paper from each of the following universities: University of Arizona, University of Arkansas, Ball State University, Cornell University, University of Georgia, University of Illinois, Johns Hopkins University, Kansas State University, Michigan State University, University of Mississippi, University of Missouri, Montana State University, New Mexico State University, Ohio State University, Purdue University, University of Tennessee, University of Vermont, Washington State University.

U.S. Salinity Laboratory, Soil Conservation Service, Highway Research Board of the National Research Council, and the Agricultural Research Service in Washington, D.C.]; one private company (Monsanto Chemical Company), and 13 university laboratories (Utah State, Iowa State, Cornell, University of Missouri, University of California-Berkeley, University of California-Davis, Purdue, Michigan State, University of Alaska, Ohio State, University of North Carolina, Washington State University, and University of Wisconsin).
T a b l e 3. Topics considered in non-methods papers published in the Soil Physics Division of the Soil Science Society of America Journal between 2005 and 2011

\begin{tabular}{|c|c|}
\hline Topic & Number of papers \\
\hline \multicolumn{2}{|c|}{ Four main topics* } \\
\hline Water & 48 \\
\hline Mechanical properties & 35 \\
\hline Aeration & 19 \\
\hline Temperature & 10 \\
\hline \multicolumn{2}{|c|}{ Other topics } \\
\hline Solute transport & 18 \\
\hline Plants considered & 16 \\
\hline Repellency & 14 \\
\hline Erosion & 10 \\
\hline Infiltration & 8 \\
\hline Pedotransfer functions & 7 \\
\hline Tillage & 7 \\
\hline Organic soils, organic matter & 7 \\
\hline Evaporation & 4 \\
\hline Soil mapping & 4 \\
\hline Runoff, polyacrylamide & 4 \\
\hline Adsorption (not pesticides) & 3 \\
\hline Irrigation with effluents & 3 \\
\hline Preferential flow & 3 \\
\hline Pesticide sorption & 2 \\
\hline Clay soils & 1 \\
\hline Gravity & 1 \\
\hline Solarization to control pests & 1 \\
\hline
\end{tabular}

*As enumerated by Shaw (1952).

Now let us turn to the research done in these 299 papers. I have tried to categorize them based on keywords in the titles. Seventy-five percent of the papers were non-methods papers (Table 3 ), and 25\% were methods papers (Table 4). As shown in Table 3, 48 (16\% of the papers) dealt with water, 35 (12\%) with mechanical properties, 19 (6\%) with aeration, and $10(3 \%)$ with temperature. Other topics now being widely investigated include solute transport (18 papers) and repellency (14 papers) (Table 3 ). Many new methods are being investigated, too, with time domain reflectometry (24 papers) being the most studied one (Table 4).

It is interesting to compare the topics covered between 2005-2011 with those covered between 1961-1985, as cited by Cassel (1986). Water is still the most important topic. Between 1961 and 1985, an average of $57.6 \%$ of the papers dealt with water (Cassel, 1986), compared to $48 \%$ in my survey. In the survey by Cassel (1986), the topics of solids, heat, 
T a b l e 4. Topics considered in methods papers published in the Soil Physics Division of the Soil Science Society of America Journal between 2005 and 2011

\begin{tabular}{lc}
\hline Topic & Number of papers \\
\hline Time domain reflectometry & 24 \\
Heat pulse & 7 \\
Tension infiltrometers & 7 \\
Capacitance probes & 5 \\
Infrared spectra & 5 \\
X-ray computed tomography & 4 \\
Permittivity measurements & 3 \\
Soil sampling methods & 4 \\
Tension controlled suction plates & 3 \\
Electrical resistivity measurements & 2 \\
Determination of wetting front & 1 \\
Dye traces & 1 \\
Electromagnetic induction (to measure elec. & 1 \\
cond.) & 1 \\
Impedance probes & 1 \\
Nuclear magnetic resonance relaxometry & 1 \\
Resistance sensors (to measure matric & 1 \\
potential) & 1 \\
Soil air oxygen sensors & 1 \\
Tensiometers & 1 \\
Thermal analysis & 1 \\
Wick samplers & \\
\hline & 1 \\
\hline
\end{tabular}

T a b l e 5. Funding for non-USA papers, in which funding was acknowledged and which were published in the Soil Physics Division of the Soil Science Society of America Journal between 2005 and 2011

\begin{tabular}{lc}
\hline Source of funding & Number of papers \\
\hline Government of corresponding author & 125 \\
European Union* & 6 \\
EnCana Corp., Calgary, Alberta, Canada & 2 \\
OECD** & 1 \\
US Agency for International Development & 1 \\
No source given*** & 51 \\
\hline
\end{tabular}

*Three of the EU projects were funded by FEDER (Fonds Européen de développement régional).

**Organization for Economic Cooperation and Development.

$* * *$ Country and number of papers for which no source of funding given: Germany -8 , Israel -6 , Belgium -5 , Canada -4 , P.R. of China - 4, France - 4, Japan - 4, Australia - 2, India - 2, New Zealand - 2, Brazil - 1, Denmark - 1, England - 1, Finland - 1, Greece - 1, Hong Kong - 1, Italy - 1, Poland - 1, Switzerland - 1, Taiwan -1 . and air comprised $12.0,7.9$, and $4.2 \%$ of the papers, respectively. In my survey, the topics of mechanical properties, temperature, and aeration comprised 12,3 , and $6 \%$ of the papers, respectively.

Now let us look at funding of the research. Of the nonUSA papers (Table 5), 51 of the 186 papers (27\%) gave no source of funding. Of the remaining 135, 125 were funded by the government of the corresponding author. The other ten were funded by the European Union (6); the Organization for Economic Cooperation and Development (1); the U.S. Agency for International Development (1); and a private company, EnCana Corp. in Canada (2).

Now let us look at the source of funding for the papers with corresponding authors in the USA. Of the 33 papers from USDA laboratories, 27 acknowledged no source of funding. Of the 74 papers published by universities, 26 acknowledged no source of funding. Funding for the other papers (Table 6) usually came from multiple sources. Twelve papers cited support from State Agricultural Experiment Station funds (Table 6), and only two of the twelve cited Agricultural Experiment Station funds as the sole support (Utah State, University of Wisconsin).

It appears that, unlike the USA, other countries, especially the People's Republic of China, are investing more in agricultural research than the USA. For example, The Chinese government is funding its young scientists with programs such as 'One Hundred Talent Program', 'Program for Changjiang Scholars and Innovative Research Team in University', and the 'Program for New Century Excellent Talent in Universities'. Many of the Chinese papers in the survey were supported by these programs.

\section{CONCLUSIONS}

The survey of the 299 soil-physics papers published in the USA between 2005 and 2011 showed that there was an average of 3.5 authors per paper; women were authors on about $14 \%$ of the papers; $62 \%$ of the papers (186 papers) came from 29 foreign countries, and, of the remaining $38 \%$ of the papers (113 domestic ones), 13\% were published by federal laboratories and $25 \%$ were published by 35 university laboratories. Methods papers comprised $25 \%$ of the papers. The other $75 \%$ considered many topics including the four main subjects studied by soil physicists: soil water (16\% of the papers); mechanical properties $(12 \%)$; soil aeration (6\%); and soil temperature (3\%). Of the non-USA papers, $27 \%$ gave no source of funding and the other $73 \%$ usually cited funding by the government of the authors. Of the USA papers, 27 federal-laboratory papers and 26 universitylaboratory papers cited no source of funding for a total of $47 \%$, and the other $53 \%$ usually cited multiple sources of funding for each paper. The results showed that soil-physics research published in the USA has become heavily international. 
T a b l e 6. Funding for USA papers, in which funding was acknowledged and were published by universities in the Soil Physics Division of the Soil Science Society of America Journal between 2005 and 2011

\begin{tabular}{|c|c|c|c|}
\hline Source of funding & $\begin{array}{l}\text { No. of } \\
\text { papers }\end{array}$ & Source of funding & $\begin{array}{l}\text { No. of } \\
\text { papers }\end{array}$ \\
\hline \multicolumn{2}{|l|}{ Federal funds } & \multicolumn{2}{|l|}{ State funds } \\
\hline USDA* & 19 & State of Iowa & 3 \\
\hline National Science Foundation & 16 & Kansas State Univ. Targeted Excellence Program & 2 \\
\hline National Aeronautics and Space Administration & 4 & Colorado State Univ. & 1 \\
\hline BARD** & 2 & Desert Research Institute & 1 \\
\hline Bureau of Reclamation & 2 & Pennsylvania Department of Agriculture & 1 \\
\hline Army Research Office & 1 & Pennsylvania State Fund for Research & 1 \\
\hline Bureau of Land Management & 1 & Southwest Florida Water Management District & 1 \\
\hline CASMGS** & 1 & Univ. of Hawaii Water Resources Research Center & 1 \\
\hline EPSCoR** & 1 & Univ. of Wisconsin Geography Department & 1 \\
\hline U.S. Department of Education Fellowship & 1 & Virginia Water Resources Research Center & 1 \\
\hline U.S. Environmental Protection Agency & 1 & \multirow[t]{2}{*}{ Wyoming Department of Agriculture } & \multirow[t]{2}{*}{1} \\
\hline Water Resources Research Act of USGS** & 1 & & \\
\hline \multicolumn{2}{|l|}{ State Agricultural Experiment Station Funds } & \multicolumn{2}{|l|}{ Private sources } \\
\hline Hatch Funds (Iowa State; Univ. Hawaii and Wis.) & 5 & Alvin H. Baum Family Fund (to Univ. Illinois) & 1 \\
\hline Utah State Univ. & 3 & Cave Conservancy Fund & 1 \\
\hline Univ. of Illinois & 1 & Kearney Foundation (California) & 1 \\
\hline Univ. of Kentucky & 1 & Microsoft Research & 1 \\
\hline New Mexico State Univ. & 1 & Turfgrass Council of North Carolina & 1 \\
\hline Pennsylvania State Univ. & 1 & Weyerhauser & 1 \\
\hline
\end{tabular}

*Includes Cooperative State Research, Education, and Extension Service (CSREES) - 5; National Research Initiative (NRI) - 3; USDA Specific Cooperative Agreements - 2; USDA Forest Service - 2; USDA Dale Bumpers Small Farm Research Center - 1; USDA Higher Education Challenge Competitive Grant Program - 1: USDA-ARS Pecan Initiative - 1; USDA Rio Grande Basin Initiative - 1; and USDA (no specific source of funding given) -3 .

**Abbreviations: BARD, U.S. - Israel Binational Agricultural Research and Development Fund; CASMGS, Consortium for Agricultural Soils Mitigation of Greenhouse Gases; EPSCoR, Experimental Program to Stimulate Competitive Research; USGS, U.S. Geological Survey.

\section{REFERENCES}

Cassel D.K., 1986. Highlights of research in Division S-1, Soil Physics. Soil Sci. Soc. Am. J., 50, 1093-1094.

Kirkham D., 1961. Soil physics 1936-1961 and a look ahead. Soil Sci. Soc. Am. Proc., 25, 423-427.
Shaw B.T. (Ed.), 1952. Preface. In: Soil Physical Conditions and Plant Growth. Agronomy. Monographs, Vol. II. ASA, Academic Press, New York, USA.

Stengel R. (Managing Editor), 2011. Another way China may beat the U.S. Time, 177(14), 15.

Tullo A.H., 2011. Women in industry. Chem. Eng. News, 89(32), $22-23$. 